OPEN ACCESS

Edited by: Andrea Dorigato, University of Trento, Italy

Reviewed by: Liqing Wei,

United States Forest Service (USDA),

United States

Arup R. Bhattacharyya, Indian Institute of Technology

Bombay, India

${ }^{*}$ Correspondence:

Bluma G. Soares

bluma@metalmat.ufri.br

Specialty section:

This article was submitted to Polymeric and Composite Materials,

a section of the journal

Frontiers in Materials

Received: 20 March 2019

Accepted: 24 July 2019

Published: 09 August 2019

Citation:

Soares da Silva JP, Soares BG,

Silva AA and Livi S (2019) Double Percolation of Melt-Mixed PS/PBAT

Blends Loaded With Carbon

Nanotube: Effect of Molding

Temperature and the Non-covalent Functionalization of the Filler by lonic

Liquid. Front. Mater. 6:191.

doi: 10.3389/fmats.2019.00191

\section{Double Percolation of Melt-Mixed PS/PBAT Blends Loaded With Carbon Nanotube: Effect of Molding Temperature and the Non-covalent Functionalization of the Filler by Ionic Liquid}

\author{
Jéssica P. Soares da Silva ${ }^{1}$, Bluma G. Soares ${ }^{1,2 *}$, Adriana A. Silva ${ }^{3}$ and Sebastien Livi ${ }^{4}$ \\ 1 Instituto de Macromoléculas, Universidade Federal do Rio de Janeiro, Rio de Janeiro, Brazil, ${ }^{2}$ PEMM-COPPE, Universidade \\ Federal do Rio de Janeiro, Rio de Janeiro, Brazil, ${ }^{3}$ Escola de Química, Universidade Federal do Rio de Janeiro, \\ Rio de Janeiro, Brazil, ${ }^{4}$ CNRS, UMR 5223, Ingenierie des Materiaux Polymeres, INSA Lyon, Villeurbanne, France
}

Polystyrene/poly(butylene adipate-co-terephthalate) (PS/PBAT) composites loaded with different amounts of carbon nanotube (CNT) were prepared by melt mixing followed by compression molding at different temperatures. The effect of the non-covalent functionalization of CNT with the ionic liquid (IL), trihexyl(tetra decyl)-phosphonium bis-triflimide on the electrical and rheological properties of the composites with co-continuous morphology was investigated. The AC electrical conductivity of the composites loaded with 0.16 wt.\% of pristine CNT jumped from $10^{-7}$ to $10^{-3} \mathrm{~S} / \mathrm{m}$ by increasing the molding temperature from 180 to $200^{\circ} \mathrm{C}$. Moreover, conductivity as high as $0.8 \mathrm{~S} / \mathrm{m}$ was achieved in composite containing $0.66 \mathrm{wt} . \%$ of CNT. The outstanding electrical performance was attributed to the double percolation and the selective localization of CNT within PBAT phase. The functionalization with IL resulted in an increase of the conductivity for composites containing low amount of filler IL-functionalized CNT resulted in a decrease of the melt viscosity and storage modulus due to the plasticizing effect of IL. However, for the system containing IL/CNT = 5:1 wt.\%, the modulus increased significantly due to the formation of the percolated networked structure of the filler within the polymer matrix.

Keywords: ionic liquid, electric conductivity, polymer blend, carbon nanotube, rheology, biodegradable polymer

\section{INTRODUCTION}

Blending a thermoplastic polymer with conductive filler using melt processing approach is by far one of the cheapest and most technically viable alternatives to producing conductive composites. These materials have been attracted enormous interest for several decades due to the possibility of developing processable materials with controlled electrical conductivity for applications in important industrial sectors, as antistatic, electrostatic charge dissipating materials, as well as, electromagnetic interference shielding and micro-wave absorbing materials. The electrical properties of these materials can be improved by appropriate choice of the polymer matrix, 
processing conditions, as well as the nature of the conductive filler. In this context, carbon nanotubes (CNT) have been focus of increasing interest due to their unique mechanical, electrical and thermal properties (Spitalsky et al., 2010). Furthermore, their large aspect ratio contributes to the corresponding composites achieving high conductivity level with lower proportion of the filler. CNT-loaded thermoplastics can be obtained by different techniques, including solution process, dispersion in polymers in the latex form, in situ polymerization and melt mixing procedure. The last one has been considered the most versatile for technological and industrial purposes because of its low cost, being easily scalable using conventional processing equipments (Lim et al., 2010; Rios-Fachal et al., 2013; Soares da Silva et al., 2017).

In order to achieve lower percolation threshold in the polymer matrix, the CNT must be uniformly and properly dispersed to form the conducting pathway. However, the dispersion of CNT in thermoplastic matrices through melt mixing approach is somewhat difficult due to the strong tendency of CNT to agglomerate in bundles and ropes. To overcome these drawbacks, several approaches have been considered in the literature. Some of them involve some modification in the melt-mixing protocol, including processing time and temperature (Tambe et al., 2013). Non-covalent modification of CNT with organic compounds and polymers also contributes for an improved dispersion of CNT within a polymer matrix, without deteriorating the electrical properties of CNT (Sahoo et al., 2010; Roy et al., 2012). For example, Bhattacharyya et al. encapsulated single walled carbon nanotube (SWCNT) with styrene-maleic anhydride copolymer and used in blends with polyamide 12 (Bhattacharyya et al., 2007). The authors achieved good filler dispersion but a decrease of electrical conductivity due to the formation of a polymer layer surrounding the CNT, thus avoiding contact each other. Other organic molecules as sodium salt of 6-aminohexanoic acid (Bose et al., 2008, 2009) and 1-pyrene-carboxaldehyde (Poyekar et al., 2015a) were employed to modify CNT in order to improve the dispersion in thermoplastic matrices. In these cases, a significant enhancement in electrical conductivity was observed by using both modifier agents. Considering similar strategy for dispersing CNT within polymeric matrices, the use of ionic liquids as surface modifiers for CNTs appeared as an innovative approach for dispersing $\mathrm{CNT}$ in polymeric matrices without destroying the conjugation at the surface, responsible for the conductivity. Some reports deals with the treatment of CNT with imidazolium-based ionic liquids to improve the dispersion of CNT in some thermoplastic matrices as well as, the filler-matrix interaction (Bellayer et al., 2005; Zhao et al., 2012; Sharma et al., 2014; Chen et al., 2015; Soares, 2018). Recently, alkyl phosphonium-based ionic liquids was also considered for assisting the CNT dispersion in polystyrene (PS) matrix (Soares da Silva et al., 2017), as well as polypropylene (PP)/polyamide12 (PA12) (Lopes Pereira et al., 2019) and PS/ ethylene-vinyl acetate copolymer (EVA) (Soares et al., 2018) blends. A significant increase in conductivity by several orders of magnitude was observed for PS/CNT composites using the trihexyl (tetradecyl) phosphoniumbistriflimide (Soares da Silva et al., 2017).
The lowering of the percolation threshold was also achieved using heterogeneous polymer blends as matrices due to the uneven distribution of the filler in these phases (Sumita et al., 1991). By choosing a blend composition whose phase containing the percolated conductive filler is continuous or a blend with co-continuous structure, the amount of required conductive filler for attaining the insulator-conducting transition (percolation threshold) is usually lower that that employed in single polymer matrix. This phenomenon is known as double percolation and has been reported for several CNT-loaded thermoplastic binary blends, including acrylonitrile-butadienestyrene (ABS) copolymers with PA6 (Poyekar et al., 2014, 2015a,b), ABS/ polycarbonate (PC) (Xiong et al., 2013), poly(Llactide) (PLA)/(EVA) (Shi et al., 2013), PS/PP (Hwang et al., 2012), PS/PE (Patra et al., 2015), PS/polyvinylidene fluoride (PVDF) (Ren et al., 2017), PS/EVA (Soares et al., 2018), and PS/PLA (Nasti et al., 2016).

PS is a versatile and inexpensive commodity polymer with good mechanical properties, optical transparency, and processability, being chosen by several researchers as a matrix for the development of melt-mixing conductive composites (Zeimaran et al., 2015; Kausar et al., 2017) loaded with carbonbased fillers as carbon black (Soares et al., 1995, 1998, 2016), expanded graphite (Goyal et al., 2009), graphene (Bai et al., 2018), and carbon nanotube (Lim et al., 2010; Rios-Fachal et al., 2013; Soares da Silva et al., 2017). This thermoplastic is well known by its non-biodegradability. Therefore, blending PS with biodegradable polymers constitutes a promising strategy for rendering better biodegradability to the corresponding blend. These semi-biodegradable blends are known to degrade by a process known as biodisintegration, where the nonbiodegradable phase is transformed in very small pieces due to the biodegradation of the other phase (Sarasa et al., 2009). Semibiodegradable PS blends involving PLA were reported in the literature (Nasti et al., 2016; Kaseem and Ko, 2017; Gu et al., 2018). However, to the best of the authors' knowledge, no studies regarding PS/poly (butylene adipate-co-terephthalate) (PBAT) blends and the corresponding conductive composites have been found in the accessible literature.

PBAT, a fully biodegradable aliphatic-aromatic copolyester originated from petrochemical resources, is a flexible and low modulus copolymer. Therefore, the PS/PBAT blends should combine the toughness and biodegradability imparted by PBAT and the stiffness originated from PS. Furthermore, the corresponding blend and composites are cost-effective as compared with pure biodegradable polymer. Adding CNT in biodegradable or semi-biodegradable polymer blends enlarges the field of application of these materials in electro-electronic industries and packages with dissipating electrostatic charge characteristics and microwave absorbing or electromagnetic shielding properties.

Based on the profitable results reported with heterogeneous blends loaded with CNT, the motivation of the present work is to extent this approach to a semi-biodegradable PS/PBAT blends. The present work highlights the superior conductivity levels achieved by using low amount of CNT, $<1$ wt.\%, in these PS/PBAT blends with co-continuous morphology. The 
effect of the compression molding temperature and the noncovalent functionalization of CNT with Trihexyl(tetradecyl)phosphoniumbistriflimide (Ph-TFSI) as the ionic liquid on the electrical properties of these composites was also discussed. The morphology and rheological properties of these systems were also discussed in details.

\section{EXPERIMENTAL SECTION}

\section{Materials}

Poly (butylene adipate-co-terephthalate) (PBAT) (density = $1.26 \mathrm{~g} . \mathrm{cm}^{-3}$; molar mass $=79,550 \mathrm{~g} \cdot \mathrm{mol}^{-1}$; glass transition temperature $=-33^{\circ} \mathrm{C}$ ) produced by BASF (Germany) under the trade name of Ecoflex was purchased by OEKO Bioplasticos, Brazil. Polystyrene (PS) was fabricated by companhia de Estireno do Brasil (melt flow index was determined according ASTM D1238 as $6.13 \mathrm{~g} / 10 \mathrm{~min}$ at $200^{\circ} \mathrm{C} / 2.16 \mathrm{Kg}$ ) Trihexyl(tetradecyl)phosphoniumbistriflimide (Ph-TFSI) as the ionic liquid (density $=1.07 \mathrm{~g} \mathrm{~cm}^{-1}$ ) was kindly supplied by Cytec Inc. MWCNT(NC7000) was kindly supplied by Nanocyl (average diameter $=9.5 \mathrm{~nm}$; average length $=1.5 \mu \mathrm{m}$; carbon purity $=$ $90 \%$; surface area $=250-300 \mathrm{~m}^{2} / \mathrm{g}$; density $=1.67 \mathrm{~g} \mathrm{~cm}^{-1}$ ).

\section{Composite Preparation}

PS and PBAT were previously dried overnight at $70^{\circ} \mathrm{C}$. CNT was first dispersed in ionic liquid (Ph-TFSI) in a mortar for about $20 \mathrm{~min}$, obtaining a black paste. The mixtures were performed by introducing all blend components into the W50 EHT internal mixer of a Brabender Plastograph equipped with roller rotors. The blends were compounded at $170^{\circ} \mathrm{C}$ for $10 \mathrm{~min}$ at $60 \mathrm{rpm}$. The CNT-based composites were prepared under the same processing conditions, by adding the CNT or the IL-CNT paste together with the polymer components. After this step, the materials were milled and compression-molded at 180 or $200^{\circ} \mathrm{C}$ and $6 \mathrm{MPa}$ for $5 \mathrm{~min}$ and immediately cooled at the same pressure.

\section{Characterization}

A Physica MRC 302 rheometer from Anton Paar was employed to measure the rheological properties. The measurements in oscillatory mode were made using parallel plates with $25 \mathrm{~mm}$ diameter and a gap of $1.0 \mathrm{~mm} ; 200^{\circ} \mathrm{C}$; frequency range from 0.1 to $100 \mathrm{~Hz}$ and amplitude of $0.1 \%$, which is within the linear viscoelastic region.

Scanning electron microscopy was performed on a TESCAN (Vega 3 model) at $15 \mathrm{kV}$. The samples were cryogenically fractured and treated with aqueous solution of $\mathrm{NaOH}$ (5 wt.\%) in order to selectively extract the PBAT phase. Then, the surface was coated with thin layer of gold before analysis.

The AC electrical conductivity $\left(\sigma_{\mathrm{AC}}\right.$ ) was measured in a frequency range from $0.1 \mathrm{~Hz}$ to $10 \mathrm{MHz}$ using a Solartron SI 1260 gain phase analyzer interfaced to a Solartron 1296 dielectric interface. The measurements were made at $25^{\circ} \mathrm{C}$, using electrodes with $25 \mathrm{~mm}$ diameter and oscillating voltage of $5 \mathrm{~V}$. Samples of $1 \mathrm{~mm}$ thickness were prepared by compression molding at $180^{\circ} \mathrm{C}$ or $200^{\circ} \mathrm{C}$.

Transmission electron microscopy was obtained using a Tecnai Spirit from Fei Company, operating at $120 \mathrm{kV}$, localized at the Centro Nacional de Bioimagens-CENABIO/UFRJ (Brazil). The samples were cut using a Leyca ultracryomicrotome equipped with diamond knife. Samples with thickness about 60-90 nm were obtained.

\section{RESULTS AND DISCUSSION}

\section{Rheology}

Rheology is an important way for characterizing the microstructure of a nanocomposite due to the great dependence of the main viscoelastic properties of the nanocomposites in the melt state on the filler dispersion state and filler-matrix interaction. The dependence of the complex viscosity, $\eta^{*}$, with frequency for PS, PBAT, and the neat blend is illustrated in Figure 1. PBAT presented lower $\eta^{*}$ than PS at low frequency and a greater Newtonian behavior. The blend presented intermediary viscosity at low frequency, and a higher shear thinning effect, resulting in lower viscosity than the pure components at higher frequency.

The effect of pristine CNT (pCNT) and the IL-modified CNT (IL-CNT) on the $\eta^{*}$ of the composites is illustrated in Figure 2. The main rheological parameters are also summarized in Table $\mathbf{1 .}$ In both loaded systems, the viscosity at lower frequencies increased as the amount of the filler increased. However, for composites containing lower amount of pCNT (up to $0.33 \%$ ), the viscosity values were lower than that observed for the neat PS/PBAT blend. This behavior was even more pronounced for the composites containing IL-CNT. Similar feature was also reported by Lin et al in their studies involving PP/CNT nanocomposites and was attributed to the increase of the free volume around the CNT due to a better dispersion state of the filler (Lin et al., 2015). The free volume acts as a lubricant during the molecular chain flowing. The effect is more pronounced for the composites

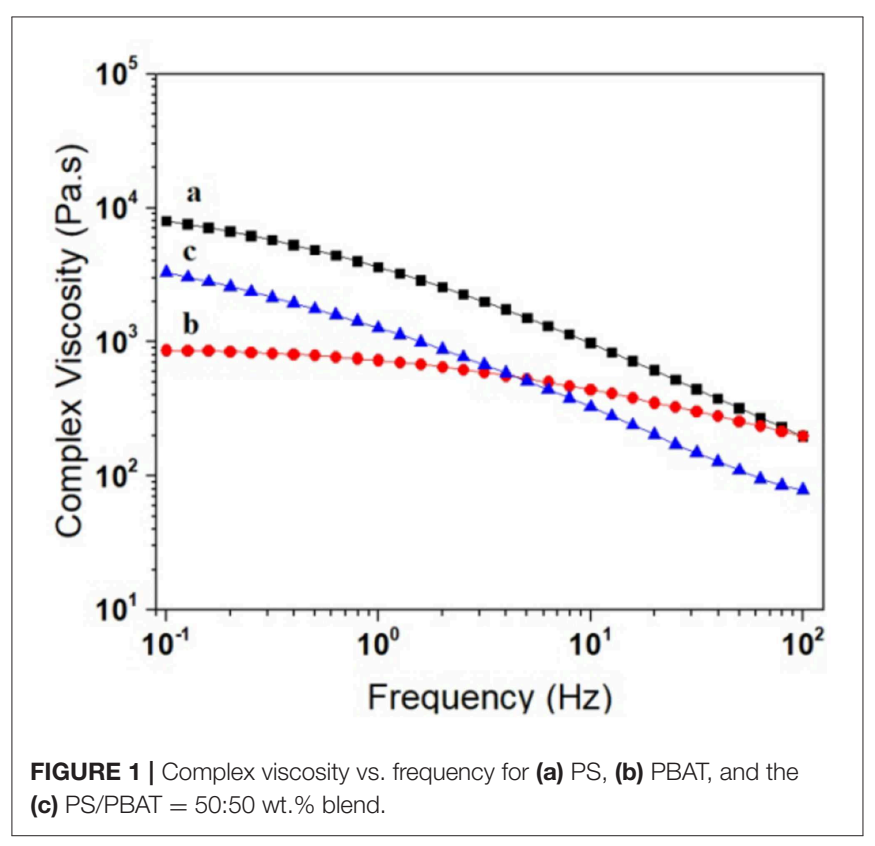



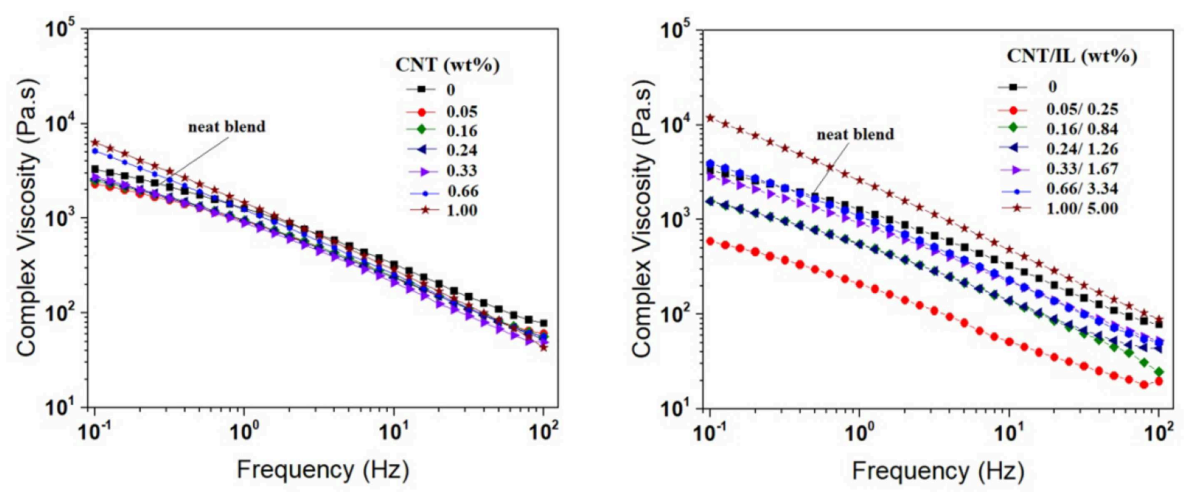

FIGURE 2 | Complex viscosity vs. frequency for the PS/PBAT composites as a function of the filler content.

TABLE 1 | Main rheological parameters of PS/PBAT composites as a function of the filler content.

\begin{tabular}{|c|c|c|c|c|c|c|c|c|}
\hline \multirow{2}{*}{$\begin{array}{l}\text { Filler content } \\
\text { (wt.\%) }\end{array}$} & \multicolumn{2}{|c|}{$\eta^{\star}$ at $1 \mathrm{~Hz}$ (Pa.s) } & \multicolumn{2}{|c|}{$\mathrm{G}^{\prime}$ at $0.1 \mathrm{~Hz}(\mathrm{~Pa})$} & \multicolumn{2}{|c|}{ Frequency at G' = G” (Hz) } & \multicolumn{2}{|c|}{ G' slope at low frequency } \\
\hline & pCNT & IL-CNT & pCNT & IL-CNT & pCNT & IL-CNT & pCNT & IL-CNT \\
\hline 0 & \multicolumn{2}{|c|}{3,340} & \multicolumn{2}{|c|}{785} & \multicolumn{2}{|c|}{1.45} & \multicolumn{2}{|c|}{0.55} \\
\hline 0.05 & 2,300 & 600 & 570 & 180 & & & 0.55 & 0.51 \\
\hline 0.16 & 2,500 & 1,560 & 750 & 500 & 1.10 & 1.08 & 0.52 & 0.48 \\
\hline 0.24 & 2,600 & 1,560 & 840 & 560 & 0.90 & 0.89 & 0.49 & 0.50 \\
\hline 0.33 & 2,700 & 2,880 & 970 & 1,100 & 0.58 & 0.58 & 0.46 & 0.46 \\
\hline 0.66 & 5,150 & 3,900 & 2,450 & 1,690 & - & - & 0.36 & 0.39 \\
\hline 1.00 & 6,300 & 11,900 & 3,050 & 5,850 & - & - & 0.31 & 0.30 \\
\hline
\end{tabular}

loaded with IL-CNT due to the plasticizing/lubricating role of the IL at the filler-matrix interface, as also observed in other studies (Zhao et al., 2012). Composites containing higher amount of filler ( 0.66 or 1.0 wt.\%) displayed $\eta^{*}$ values higher than that observed for the neat blend at low frequency and a greater shear thinning effect, which can be related to the formation of a percolated three-dimensional structure of the filer in the polymer matrix. The nanocomposite loaded with 1 wt.\% of IL-CNT presented the highest $\eta^{*}$ value in all frequency range studied, in spite of the higher proportion of IL. This behavior may be attributed to the formation of the filler network in higher extent due to the filler-filler interaction imparted by the IL at the CNT surface.

The dependence of the storage modulus with frequency also provides important information regarding the formation of the percolated structure. Figure 3 illustrates the G' plots vs. frequency for the composites containing different amounts of filler ( $\mathrm{pCNT}$ or IL-CNT). The storage modulus increased as the amount of pCNT increased and the slope of the G' vs. frequency curve in the low frequency region significantly deviated from a typical terminal behavior (see Table 1) for the composites containing higher amount of filler, suggesting the development of a three dimensional networked structure formed by the interconnected CNT. This structure is also responsible for the higher conductivity. The composite containing $1 \mathrm{wt} . \%$ of ILCNT displayed significantly higher G' value in all frequency range studied suggesting the formation of a percolated filler network in higher extent (Pötschke et al., 2004). This result suggests that the IL helps on debundling of the CNT thus facilitating the network formation.

The dependence of G' and G" with the frequency is illustrated in Figure 4 for the PS/PBAT composites with 0.33 and $1 \%$ of pCNT or IL-CNT. Both storage modulus $\left(G^{\prime}\right)$ and loss modulus (G”) increases with increasing in frequency. At low frequency, the composite loaded with 0.33 wt.\% of filler exhibited G" > G', which is characteristic of liquid-like behavior. At a specific frequency (cross-over frequency) G' and G" values are similar and after this frequency, $G^{\prime}>G^{\prime \prime}$, indicating the transition to solidlike behavior. The effect of the CNT content on the frequency corresponding to the $G^{\prime} / G^{\prime \prime}$ cross-over point is also summarized in Table 1. This point $\left(G^{\prime}=G^{\prime \prime}\right)$ shifted toward lower frequencies as the amount of filler increased, confirming the formation of the three dimensional network structure. The composites containing 0.66 or 1 wt. $\%$ of filler presented $G^{\prime}>G^{\prime \prime}$ in all frequency range studied, suggesting pseudo solid-like behavior, due to the development of the network formed by the CNT.

The plot related to the phase angle $\delta$ against the absolute value of the complex modulus $\left|G^{*}\right|$, known as van GurpPalmen plot, is usually employed in the literature to estimate the rheological percolation (Pötschke et al., 2004). The deviation of the $\delta$ value from $90^{\circ}$ in the low $\left|G^{*}\right|$ region suggests the elastic response of polymer chains. Figure 5 illustrates the van Gurp-Palmen plots for the composites loaded with pCNT and 

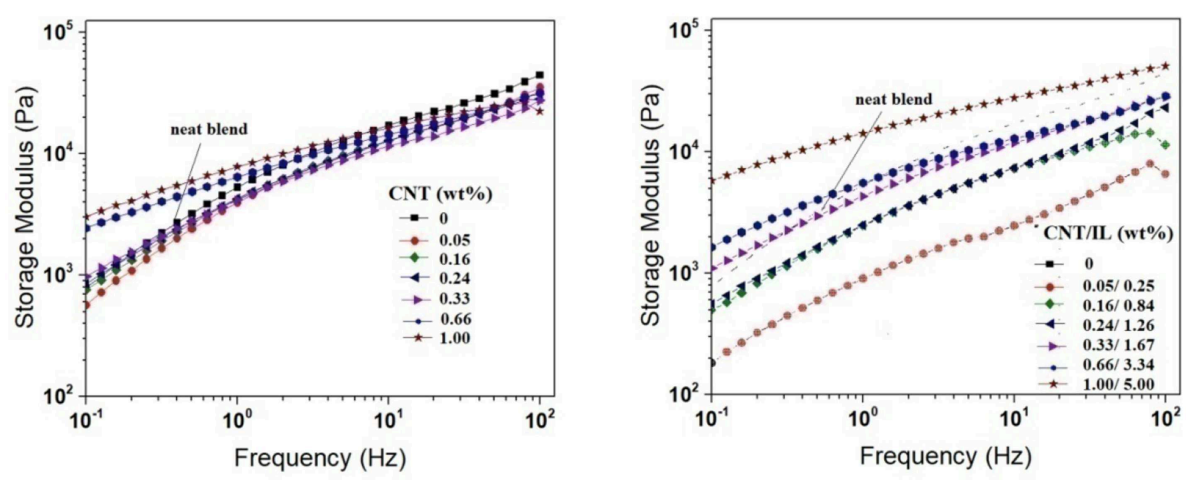

FIGURE 3 | Storage modulus vs. frequency for the PS/PBAT composites as a function of the filler content.
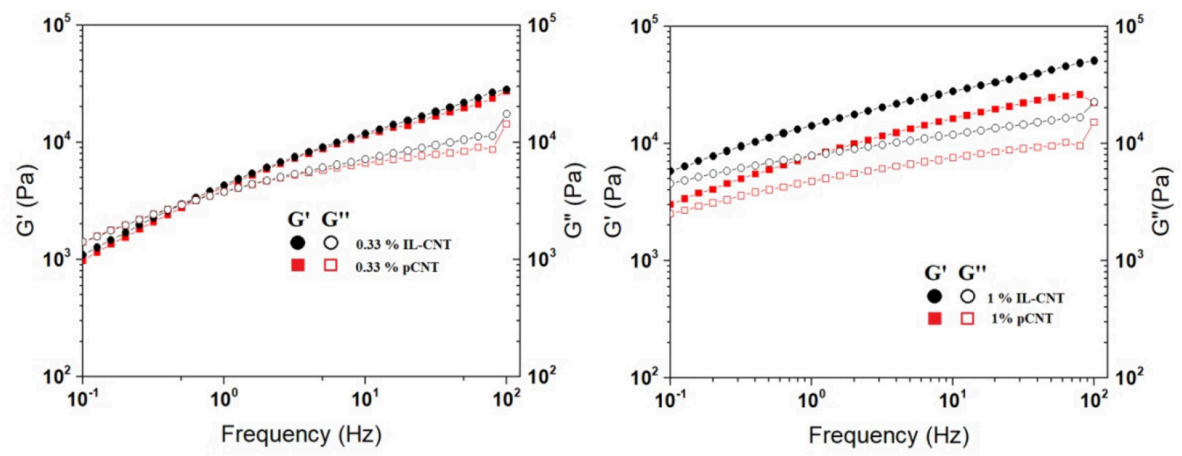

FIGURE 4 | G' and G" vs. frequency of PS/PBAT loaded with 0.33 and $1.0 \%$ of CNT.
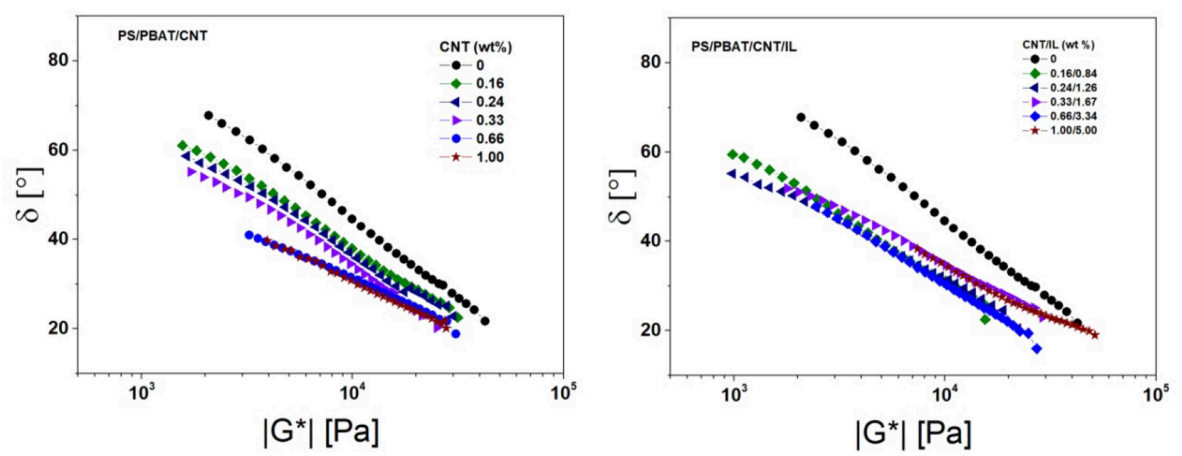

FIGURE 5 | Van Gurp-Palmen plot for the PS/PBAT composites as a function of the filler content Morphology.

IL-CNT. For a similar $\left|G^{*}\right|$, the neat PS/PBAT blend displayed the highest phase angle indicating a flow behavior. As the amount of pCNT increased, the deviation of the low range $\left|G^{*}\right|$ values to lower phase angle was observed indicating an increase of the contribution of the CNT entanglement. In this context, the composite containing 0.16 wt.\% of pCNT presented a great deviation when compared to the neat blend, indicating the rheological percolation. This value is comparable with that observed for the electrical percolation threshold. The same amount of IL-CNT (0.16 wt.\%) presented a higher deviation from the phase angle of $90^{\circ}$, indicating the formation of the network structure. These behaviors are in agreement with those observed from electrical conductivity.

The SEM micrographs of PS/PBAT blends and the composites containing 0.66 wt. $\%$ of CNT of IL-CNT are shown in Figure 6, as a function of the molding temperature. The micrographs were taken from the surfaces that were previously treated with $\mathrm{NaOH}$ solution in order to degrade 

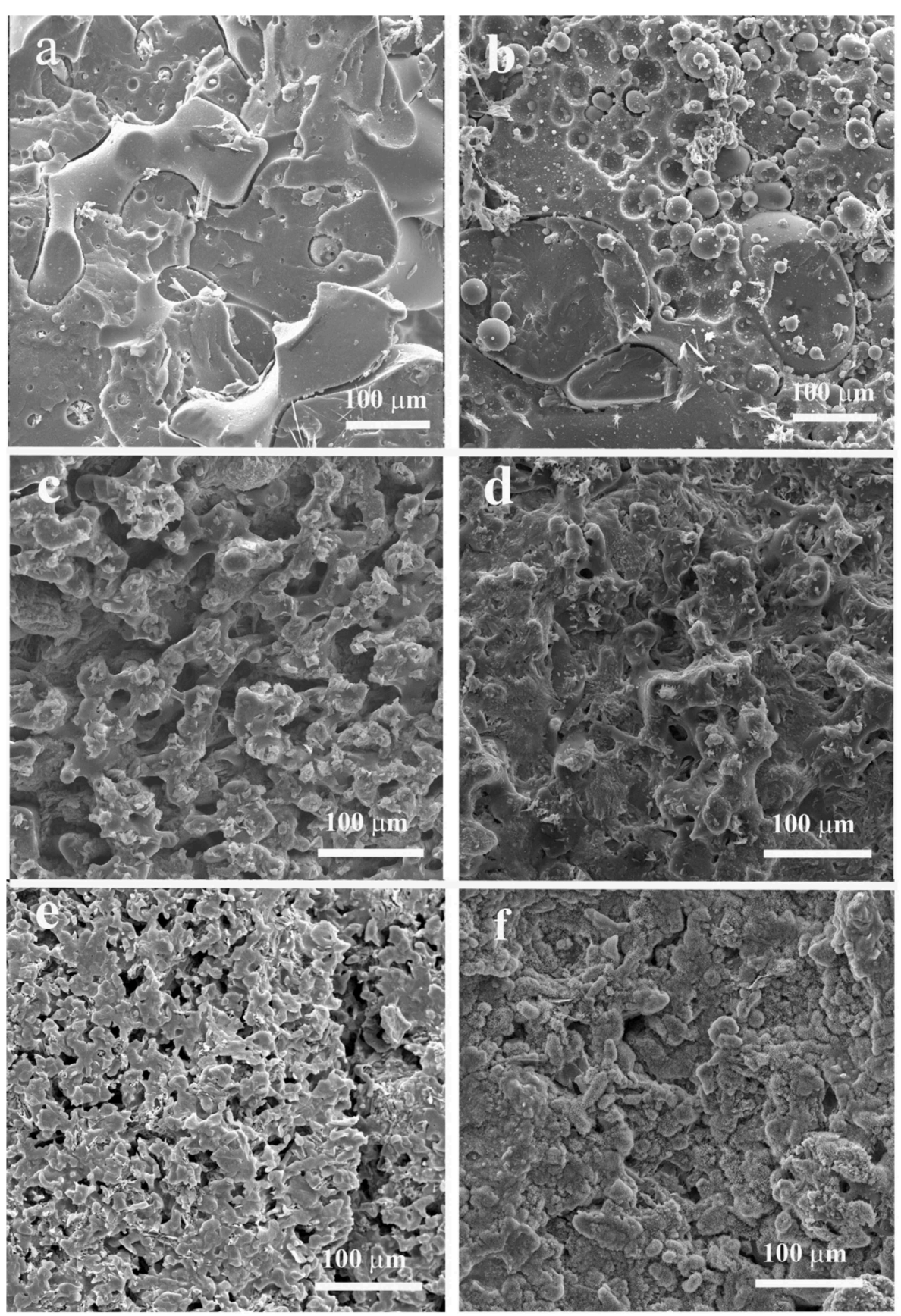

FIGURE 6 | SEM micrographs of PS/PBAT blends with (a,b) $0 \%$ of filler, (c,d) $0.66 \%$ of pCNT, and (e,f) $0.66 \%$ of IL-CNT, compression molded at $180^{\circ} \mathrm{C}$ (left column) and $200^{\circ} \mathrm{C}$ (right column).

the PBAT phase. Although the PAT phase could not be completely extracted by this method, the gross phase separated morphology with co-continuous structure can be observed for the neat blend compression molded at $180^{\circ} \mathrm{C}$ (Figure 6a). The neat blend compression molded at higher temperature displayed a sea-island type morphology characterized by large PBAT domains (Figure 6b). The presence of CNT resulted in finer co-continuous morphology, which can be attributed to the change in the viscosity ratio between the blend components, as also reported in other CNT-loaded heterogeneous blends (Gao et al., 2017; Soares et al., 2018). The co-continuous structure is more difficult to observe for the blend compression-molded at $200^{\circ} \mathrm{C}$. The presence of IL-CNT also changes the morphology of the systems suggesting a compatibilizing action of this (Ph-TFSI) -based ionic liquid. The sample compression molded at $180^{\circ} \mathrm{C}$ displayed a finer 
morphology when compared to that of the composite loaded with pCNT.

The filler dispersion in the composites was investigated by TEM microscopy. Figure 7 compares the TEM images of the composites loaded with $0.66 \%$ wt.\% of pCNT and IL-CNT, and compression molded at $200^{\circ} \mathrm{C}$. In both systems, the CNT seems to be well dispersed within the polymeric matrix. It is possible to observe even several tubes completely debundled in both systems, indicating that the dispersion of CNT in the PS/PBAT was effective, without needing the assistance of the IL.

\section{Electrical Conductivity}

The AC electrical conductivity $\left(\sigma_{\mathrm{AC}}\right)$ at $1 \mathrm{~Hz}$ for the PS/PBAT composites with different compositions and loaded with 0.66 wt.\% of CNT are summarized in Table 2. The $\sigma_{\text {AC }}$ values of the blends were superior to that observed for the single PS/CNT composite due to the contribution of double percolation and the preferential localization of CNT within the percolated PBAT phase.

The composite with a composition of PS/PBAT $=50: 50$ wt. $\%$ presented the highest $\sigma_{A C}$ value probably due to the higher degree of co-continuity at this composition.

Evidence for the preferential localization of CNT within the PBAT phase was testified from selective extraction of the PS phase using acetone. After extracting the PS phase, the solvent remained colorless indicating that the CNT was mainly localized in the non-extracted PBAT phase.

Selective localization of CNT in a given phase or at the interface of PS/PBAT blend was predicted from wetting coefficient $\left(\omega_{\mathrm{a}}\right)$ (Equation 1), determined by measuring the interfacial energy $\left(\gamma_{\mathrm{A} / \mathrm{B}}\right)$ between two components, as shown in Equation (2).

$$
\begin{aligned}
\omega_{a} & =\frac{\gamma_{P S / C N T}-\gamma_{P B A T / C N T}}{\gamma_{P S / P B A T}} \\
\gamma_{A / B} & =\gamma_{A}+\gamma_{B}-4\left[\frac{\gamma_{A}^{d} \gamma_{B}^{d}}{\gamma_{A}^{d}+\gamma_{B}^{d}}+\frac{\gamma_{A}^{p} \gamma_{B}^{p}}{\gamma_{A}^{p}+\gamma_{B}^{p}}\right]
\end{aligned}
$$

The surface energy of the blend components is listed in Table 3.

If $\omega_{\mathrm{a}}>1$, the filler is expected to be located in the PBAT phase; if $\omega_{\mathrm{a}}<-1$, the preferential localization of the filler should be in the PS phase. From thermodynamic calculations, the value of $\omega_{\mathrm{a}}$ was found to be -1.5 , indicating a preferential localization in the PS phase. The thermodynamic prediction does not agree with the experimental results. The selective localization of the filler is also governed by other kinetic parameters as well as the viscosity of the blend component. PBAT presented lower viscosity than PS and melts first, favoring the encapsulation of CNT in this phase.

The PS/PBAT (50:50 wt.\%) blend was chosen for studies involving the effect of filler content, compression-molded temperature and the non-covalent functionalization of CNT by ionic liquid. Figure 8 illustrates the dependence of the $\left(\sigma_{\mathrm{AC}}\right)$ with the frequency for the composites loaded with different amounts of pristine CNT ( $\mathrm{pCNT}$ ) and compression molded at two different temperatures: $180^{\circ} \mathrm{C}$ and $200^{\circ} \mathrm{C}$. The composite containing $0.05 \%$ of $\mathrm{CNT}$ and compression molded at $180^{\circ} \mathrm{C}$ displayed $\sigma_{A C}$ value around $10^{-10} \mathrm{~S} / \mathrm{m}$ at low frequency. Increasing the molding temperature increased the $\left(\sigma_{\mathrm{AC}}\right)$ in two orders of magnitude, reaching values around $10^{-8} \mathrm{~S} / \mathrm{m}$. In both cases, the conductivity became frequency dependent at a certain frequency, indicating the electrical conduction through hopping process. Increasing the amount of filler, the conductivity

TABLE 2 | $\sigma_{A C}$ of PS/PBAT blends with different compositions and loaded with 0.66 wt. $\%$ of CNT.

\begin{tabular}{lcc}
\hline & Blend components (wt. \%) & \\
\hline PS & PBAT & \\
\hline 100 & 0 & $\left.8 \times 10^{-6}\right)(\mathbf{S} / \mathbf{m})$ \\
70 & 30 & $4 \times 10^{-4}$ \\
50 & 50 & $5 \times 10^{-3}$ \\
30 & 70 & $2 \times 10^{-4}$
\end{tabular}
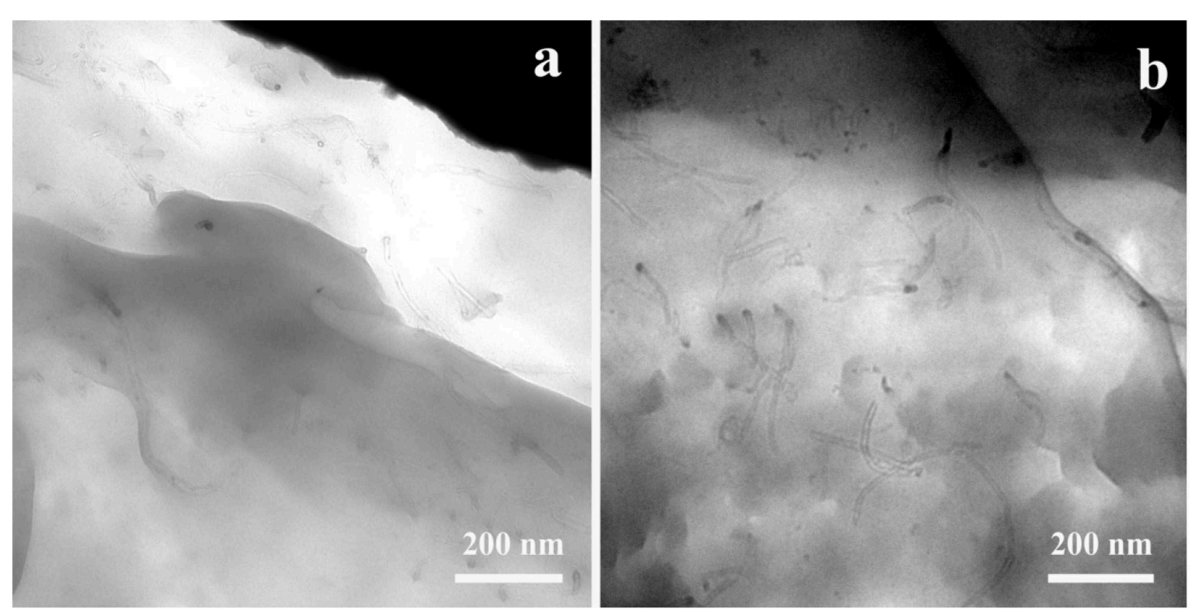

FIGURE 7 | TEM micrographs of PS/PBAT composites containing $0.66 \%$ of (a) pCNT and (b) IL-CNT, and molded at $200^{\circ} \mathrm{C}$. 
increased and became frequency independent, characterizing a conductive material. The percolation threshold may be estimated in between 0.05 and $0.16 \%$ of CNT, which is considerably lower than some other studies reported in the literature for several heterogeneous polymer blends loaded with CNT and prepared by melt mixing. Table 4 compares the conductivity of different CNT-loaded thermoplastic systems, where it is possible to observe the superior conductivity values for the system studied in the present work, with lower amount of CNT. This behavior highlights the influence of the nature of the polymer matrix to attain high conductivity levels with low amount of CNT.

The filler localized in the PBAT phase tends to flocculate during compression molding at higher temperatures and forms the conductive network. This phenomenon was also reported in others studies and suggests that the polymer composite containing conductive particles is not a thermodynamic equilibrium system, whose the formation of the conductive network is temperature and time dependent (Zhang et al., 2006).

The effect of the non-covalent functionalization of CNT by ionic liquid on the electrical conductivity of PS/PBAT blend molded at different temperatures is illustrated in Figure 9. At low filler content, the conductivity of the composites loaded with IL-CNT were higher, indicating that the presence of IL contributes for the debundling of the CNT, thus improving the formation of the conducting network with lower amount of filler, i.e., lower percolation threshold. As the amount of IL-CNT increased, the conductivity values of the composites were lower than those loaded with pristine CNT. As the IL/CNT ratio was kept as 5:1,

TABLE 3 | Surface energies of the blend component.

\begin{tabular}{lcccl}
\hline Materials & $\gamma^{\boldsymbol{d}}(\mathbf{m} \mathbf{N} / \mathbf{m})$ & $\gamma^{\boldsymbol{p}}(\mathbf{m N} / \mathbf{m})$ & $\gamma(\mathbf{m N} / \mathbf{m})$ & References \\
\hline PS & 21.64 & 6.1 & 27.74 & Rohini and Bose, 2014 \\
PBAT & 45 & 3 & 48 & Livi et al., 2016 \\
CNT & 17.6 & 10.2 & 27.8 & Barber et al., 2004 \\
\hline
\end{tabular}

$\gamma^{d}$, dispersive part; $\gamma^{d}$, polar part; $\gamma$, total surface energy. increasing the amount of filler also increased the proportion of IL. The IL in higher proportion should wrap the CNT thus forming a layer between the tubes that affects the contact each other and formation of the conducting network. Although, this is not a usual behavior for polymer composites loaded with IL-CNT, some examples in the literature also reported a decrease of conductivity by using the IL modified CNT (Sharma et al., 2014; Xu et al., 2014).

\section{CONCLUSION}

PS/PBAT (50:50 wt.\%) blend with co-continuous structure was loaded with different amounts of CNT to prepare conductive composites with AC electrical conductivity as high as $0.8 \mathrm{~S} / \mathrm{m}$ with 1 wt.\% of CNT. The CNT was preferentially localized within the PBAT phase. Although it is not the thermodynamically favored phase, the lower viscosity of this component favors the localization of the filler. The co-continuous morphology and the selective localization of the filler account for the superior electrical properties. The increasing of molding temperature also contributed for a significant improvement of the electrical conductivity. The functionalization of the CNT with ionic liquid resulted in an increase of the conductivity for composites loaded with low amount of CNT, also resulting in lower percolation threshold. Higher proportion of the functionalized CNT did not result in outstanding electrical conductivity probably due to the

TABLE 4 | Conductivity values of CNT-thermoplastic systems prepared by melt mixing.

\begin{tabular}{lccl}
\hline Polymer matrix & CNT (\%) & Conductivity (S/m) & References \\
\hline PA6/ABS (50:50) & 5 & $10^{-7}$ & Poyekar et al., 2014 \\
PLA/PCL (50:50) & 1 & $2 \times 10^{-4}$ & Huang et al., 2014 \\
PC/PVDF (60:40) & 1 & $10^{-5}$ & Biswas et al., 2015 \\
PP/PA6 (80:20) & 4 & $4 \times 10^{-5}$ & Zhang et al., 2009 \\
PLA/PBAT (60:40) & 2 & $10^{-5}$ & Urquijo et al., 2017 \\
PS/EVA (70:30) & 1 & 0.5 & Soares et al., 2018 \\
PS/PBAT (50:50) & 1 & 1.0 & This work
\end{tabular}
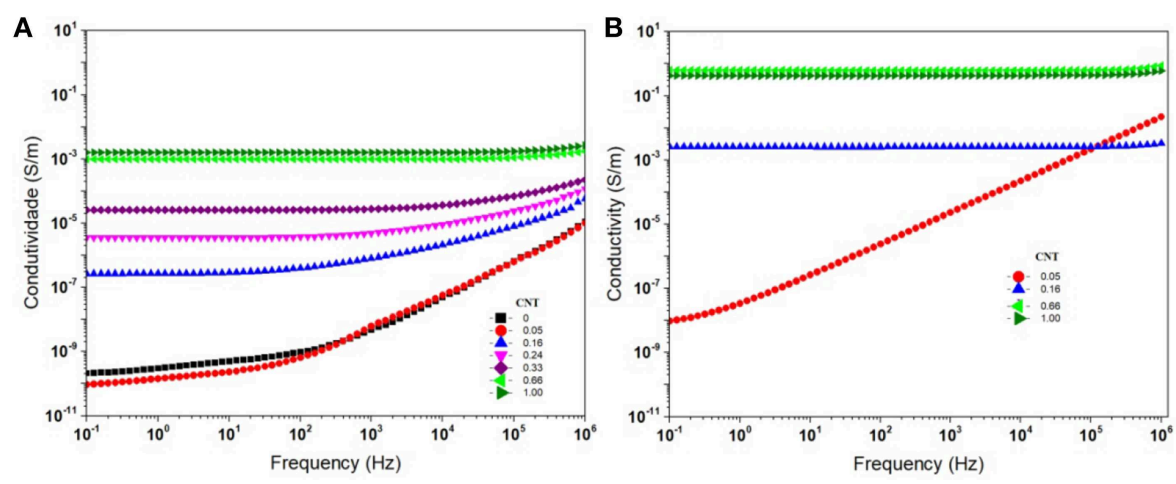

FIGURE 8 | AC conductivity of PS/PBAT composites as a function of the pCNT content. Systems compression molded at $180^{\circ} \mathrm{C}(\mathbf{A})$ and at $200^{\circ} \mathrm{C}$ (B). 


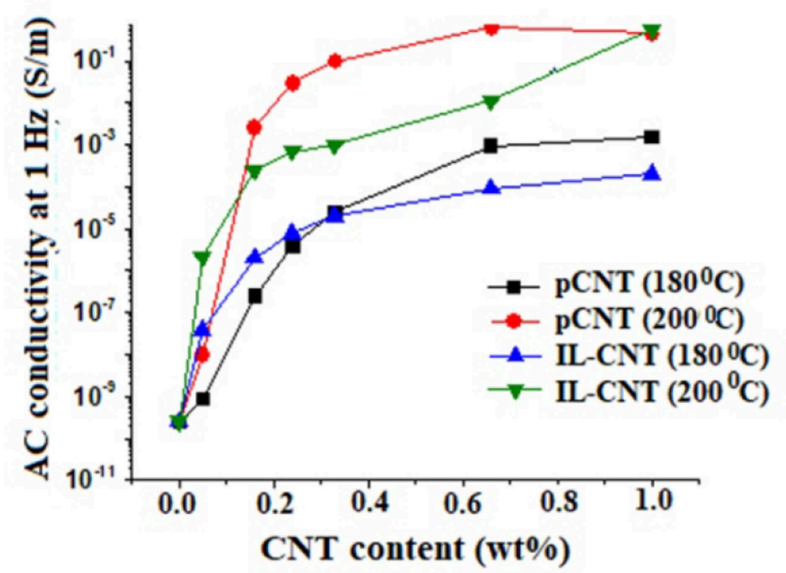

FIGURE 9 | AC conductivity at $1 \mathrm{~Hz}$ of PS/PBAT composites as a function of pCNT or IL-CNT content and molding temperature.

formation of an insulating layer of IL (in higher proportion) that wraps the CNT, thus avoiding the conductive contact.

The co-continuous morphology of the blends became thinner with the presence of the filler, due to changes in the viscosity ratio between the blend components.

The composites filled with IL-functionalized CNT displayed significantly lower viscosity in the melt state due to the plasticizing/lubricating effect of the IL at the filler-matrix interface. However, for higher amount of filler, the presence of IL resulted in significant increase of viscosity and G',

\section{REFERENCES}

Bai, L., Sharma, R., Cheng, X., and Macosko, C. W. (2018). Kinetic control of graphene localization in co-continuous polymer blends via melt compounding. Langmuir 34, 1073-1083. doi: 10.1021/acs.langmuir.7b03085

Barber, A. H., Cohen, S. R., and Wagner, H. D. (2004). Static and dynamic wetting measurements of single carbon nanotubes. Phys. Rev. Lett. 92:186103. doi: 10.1103/PhysRevLett.92. 186103

Bellayer,. S., Gilman, J. W., Eidelman, N., Bourbigot, S., Flambard, X., Fox, D. M., et al. (2005). Preparation of homogeneously dispersed multiwalled carbon nanotube/polystyrene nanocomposites via melt extrusion using trialkyl imidazolium compatibilizer. Adv. Funct. Mater. 15, 910-916. doi: 10.1002/adfm.200400441

Bhattacharyya, A. R., Bose, S., Kulkarni, A. R., Pötschke, P., Häussler, L., Fischer, D., et al. (2007). Styrene maleic anhydride copolymer mediated dispersion of single wall carbon nanotubes in polyamide 12: crystallization behavior and morphology. J. Appl. Polym. Sci. 106, 345-353. doi: 10.1002/app.26680

Biswas, S., Kar, G. P., and Bose, S. (2015). Tailor-made distribution of nanoparticles in blend structure toward outstanding electromagnetic interference shielding. ACS Appl. Mater. Interface 7, 25448-25463. doi: 10.1021/acsami.5b08333

Bose, S., Bhattacharyya, A. R., Khare, R. A., Kulkarni, A. R., and Pötschke, P. (2008). Specific interactions and reactive coupling induced dispersion of multiwall carbon nanotubes in co-continuous polyamide6/ionomer blends. Macromol. Symp. 263, 11-20. doi: 10.1002/masy.200850302

Bose, S., Bhattacharyya, A. R., Kulkarni, A. R., and Pötschke, P. (2009). Electrical, rheological, and morphological studies in co-continuous blends of polyamide 6 and acrylonitrile-butadiene-styrene with mainly in the low frequency region due to the formation of a percolated networked structure formed by the well dispersed IL-CNT. The present works confirms the possibility of attaining good conductivity levels with the addition of low amount of filler, by appropriate choice of the polymer system and processing conditions.

\section{DATA AVAILABILITY}

All datasets generated for this study are included in the manuscript and/or the supplementary files.

\section{AUTHOR CONTRIBUTIONS}

JS prepared all samples and discussed. AS was involved in all micrograph characterization. SL participated in the discussion of the results. BS was responsible for writing, discussing and organizing all manuscript, and provide all support in the laboratory for the experimental part of the manuscript. All authors contributed to manuscript revision, read and approved the submitted version.

\section{FUNDING}

This work was sponsored in part by Coordenação de Aperfeiçoamento de Pessoal de Nível Superior - Brasil (CAPES) - Financecode 001, Conselho Nacional de Desenvolvimento Científico e Tecnológico - CNPq (Grant number 303457/2013-9), and Fundação de Amparo à Pesquisa do Estado do Rio de Janeiro - FAPERJ (Grant number E-26/201.183/2014). multiwall carbon nanotubes prepared by melt-blending. Compos. Sci. Technol. 69, 365-372. doi: 10.1016/j.compscitech.2008. 10.024

Chen, G. X., Zhang, S., Zhou, Z., and Li, Q. (2015). Dielectric properties of poly(vinylidene fluoride) composites based on bucky gels of carbon nanotubes with ionic liquids. Polym. Compos. 36, 94-101. doi: 10.1002/pc.22917

Gao, T., Li, Y. Y., Bao, R. Y., Liu, Z. Y., Xie, B. H., and Yang, M. B. (2017). Tailoring co-continuous like morphology in blends with highly asymmetric compositon by MWCNTs: Towards biodegradable high-performance electrical conductive poly(l-lactide)/poly(3-hydroxybutyrate-co-4-hydroxybutyrate) blends. Compos. Sci. Technol. 152, 111-119. doi: 10.1016/j.compscitech.2017. 09.014

Goyal, R. K., Jagadale, P. A., and Mulik, U. P. (2009). Thermal, mechanical and dielectric properties of polystyrene/espanded graphite nanocomposites. J. Appl. Polym. Sci. 111, 2071-2077. doi: 10.1002/app.29042

Gu, L., Nessim, E. E., and Macosko, W. (2018). Reactive compatibilization of poly(lactic acid)/polystyrene blends and its application to preparation of hierarchically porous poly(lactic acid). Polymer 134, 104-116. doi: 10.1016/j.polymer.2017. 11.054

Huang, J., Mao, C., Zhu, Y., Jiang, W., and Yang, X. (2014). Control of carbon nanotubes at the interface of a co-continuous immiscible polymer blend to fabricate conductive composites with ultralow percolation thresholds. Carbon 73, 267-274. doi: 10.1016/j.carbon.2014.02.063

Hwang, T. Y., Yoo, Y., and Lee, J. W. (2012). Electrical conductivity, phase behavior, and rheology of polypropylene/polystyrene blends with multiwalled carbon nanotube. Rheol. Acta 51, 623-636. doi: 10.1007/s00397-0120630-1 
Kaseem, M., and Ko, Y. G. (2017). Melt flow behavior and processability of polylactic acid /polystyrene (PLA/PS) polymer blends. J. Polym. Environ. 25, 994-998. doi: 10.1007/s10924-0160873-5

Kausar, A., Ahmad, S., and Salamn, S. M. (2017). Effectiveness of polystyrene/carbon nanotube composit in electromagnetic interference shielding materials: a review. Polym. Plast. Technol. Eng. 56, 1027-1042. doi: $10.1080 / 03602559.2016 .1266367$

Lim, G. O., Min, K. T., and Kim, G. H. (2010). Effect of cooling rate on the surface resistivity of polymer/multi-walled carbon nanotube nanocomposites. Polym. Eng. Sci. 50, 290-294. doi: 10.1002/pen.21537

Lin, X., Tian, J. W., Hu, P. H., Ambardekar, R., Thompson, G., Dang, Z. M., et al. (2015). Improved dielectric performance of polypropylene/multiwalled carbon nanotube nanocomposites by solid-phase orientation. J. Appl. Polym. Sci. 132:42893. doi: 10.1002/app.42893

Livi, S., Lins, L. C., Sar, G., Gerard, J. F., and Duchet-Rumeau, J. (2016). Supercritical CO2- ionic liquids: a successful wedding to prepare biopolymer foams. ACS Sustainable Chem. Eng. 4, 461-470. doi: 10.1021/acssuschemeng.5b00969

Lopes Pereira, E. C., Soares, B. G., Silva, A. A., Farias da Silva, J. M., Barra, G. M. O., and Livi, S. (2019). Conductive heterogeneous blend composites of PP/PA12 filled with ionic liquids treatedCNT. Polym. Test. 74, 187-195. doi: 10.1016/j.polymertesting.2019. 01.003

Nasti, G., Gentile, G., Cerruti, P., Carfagna, C., and Ambrogi, V. (2016). Double percolation of multiwalled carbon nanotubes in polystyrene/polylactic acid blends. Polymer 99, 193-203. doi: 10.1016/j.polymer.2016.06.058

Patra,. R., Suin, S., Mandal, D., and Khatua, B. B. (2015). Reduction of percolation threshold of multiwall carbon nanotube (MWCNT) in polystyrene (PS)/ low-density polyethylene (LDPE)/MWCNT nanocomposites: and eco-friendly approach. Polym. Compos. 36, 1574-1583. doi: 10.1002/pc.23065

Pötschke, P., Abdel-Goad, M., Alig, I., Dudkin, S., and Lellinger, D. (2004). Rheological and dielectrical characterization of melt mixed polycarbonate-multiwalled carbon nanotube composites. Polymer 45, 8863-8870. doi: 10.1016/j.polymer.2004. 10.040

Poyekar, A. V., Bhattacharyya, A. R., Khare, R. A., Panwar, A. S., Simon, G. P., Dhar, S., et al. (2015b). Dispersion, migration, and "network-like" structure formation of multiwall carbon nanotubes in co-continuous, binary immiscible blends of polyamide6 and acrylonitrile-butadiene-styrene copolymer during simultaneous melt-mixing. Polym Eng. Sci. 55, 443-456. doi: 10.1002/pen.23904

Poyekar, A. V., Bhattacharyya, A. R., Panwar, A. S., and Simon, G. P. (2015a). Evolution of phase morphology and "network-like" structure of multiwall carbon nanotubes in binary polymer blends during melt-mixing. Polym Eng. Sci. 55:429. doi: 10.1002/pen.23897

Poyekar, A. V., Bhattacharyya, A. R., Panwar, A. S., Simon, G. P., and Sutar, D. S. (2014). Influence of noncovalent modification on dispersion state of multiwalled carbon nanotubes in melt-mixed immiscible blends. ACS Appl. Mater. Interface 6, 11054-11067. doi: 10.1021/am501737z

Ren, L., Zha, J. W., Li, R. K. Y., Shi, C. Y., and Dang, Z. M. (2017). Cocontinuous structural polystyrene /poly(vinylidene fluoride) nanocomposites with high dielectric constant and magnetic properties. Compos. Commun. 4, 24-32. doi: 10.1016/j.coco.2017.03.004

Rios-Fachal, M., Gracia-Fernandez, C., Lopez-Beceiro, J., Gomez-Barreiro, S., Tarrío-Saavedra, J., Ponton, A., et al. (2013). Effect of nanotubes on the thermal stability of polystyrene. J. Therm. Anal. Calorim. 113, 481-487. doi: 10.1007/s10973-013-3160-x

Rohini, R., and Bose, S. (2014). Electromagnetic interference shielding materials derived from gelation of multiwall carbon nanotubes in polystyrene/poly(methyl methacrylate) blends. ACS Appl. Mater. Interface 6, 11302-11310. doi: $10.1021 / \mathrm{am} 502641 \mathrm{~h}$

Roy, N., Sengupta, R., and Bhowmick, A. K. (2012). Modifications of carbon for polymer composites and nanocomposites. Prog. Polym. Sci. 37, 781-819. doi: 10.1016/j.progpolymsci.2012.02.002

Sahoo, N. G., Rana, S., Cho, J. W., Li, L., and Chan, S. H. (2010). Polymer nanocomposites based on functionalized carbon nanotubes. Prog. Polym. Sci. 35, 837-867. doi: 10.1016/j.progpolymsci.2010.03.002
Sarasa, J., Gracia, J. M., and Javierre, C. (2009). Study of the biodisintegration of a bioplastic material waste. Bioresour Technol. 100, 3764-3768. doi: 10.1016/j.biortech.2008.11.049

Sharma, M., Sharma, S., Abraham, J., Thomas, S., Madras, G., and Bose, S. (2014). Flexible EMI shielding materials derived by melt blending PVDF and ionic liquid modified MWNTs. Mater. Res. Express 1:035003. doi: 10.1088/2053-1591/1/3/035003

Shi, Y. Y., Yang, J. H., Huang, T., Zhang, N., Chen, C., and Wang, Y. (2013). Selective localization of carbon nanotubes at the interface of poly(L-lactide)/ethylene-co-vinyl acetate resulting in lowered electrical resistivity. Composites B 55, 463-469. doi: 10.1016/j.compositesb.2013. 07.012

Soares da Silva, J. P., Soares, B. G., Livi, S., and Barra, G. M. O. (2017), Phosphonium-based ionic liquid as dispersing agent for MWCNT in melt-mixing polystyrene blends: rheology, electrical properties and EMI shielding effectiveness. Mater. Chem. Phys. 189, 162-168. doi: 10.1016/j.matchemphys.2016.12.073

Soares, B. G. (2018). Ionic liquid: a smart approach for developing conducting polymer composites. A review. J. Mol. Liquids 262, 8-18. doi: 10.1016/j.molliq.2018. 04.049

Soares, B. G., Calheiros, L. F., Silva, A. A., Indrusiak, T., Barra, G. M. O., and Livi, S. (2018). Conducting melt blending of polystyrene and EVA copolymer with carbon nanotube assisted by phosphonium-based ionic liquid. J. Appl. Polym. Sci. 135:45564. doi: 10.1002/app.45564

Soares, B. G., Gamboa, K. M. N., Ferreira, A. J. B., Ueti, E., and Camargo, S. S. Jr. (1998). Effect of the mold temperature on the electrical properties of carbon black-loaded polystyrene/SB block copolymer blends. J. Appl. Polym. Sci. 69, 825-833. doi: 10.1002/(SICI)1097-4628(19980725)69:4<825::AID-APP22>3.0. $\mathrm{CO} ; 2-\mathrm{M}$

Soares, B. G., Gubbels, F., Jérôme, R., Teyssié, P., Vanlthem, E., and Deltour, R. (1995). Electrical conductivity in carbon black-loaded polystyrenepolyisoprene blends. Selective localization of carbon black at the interface. Polym. Bull. 35, 223-228. doi: 10.1007/BF00312918

Soares, B. G., Touchaleaume, F., Calheiros, L. F., and Barra, G. M. O. (2016). Effect of double percolation on the electrical properties and electromagnetic interference shielding effectiveness of carbon black-loaded polystyrene/ethylene vinyl acetate copolymer blends. J. Appl. Polym. Sci. 133:43013. doi: 10.1002/app.43013

Spitalsky, Z., Tasis, D., Papagelis, K., and Galiotis, C. (2010). Carbon nanotubepolymer composites: chemistry, processing, mechanical and electrical properties. Prog. Polym. Sci. 35, 357-401. doi: 10.1016/j.progpolymsci.2009. 09.003

Sumita, M., Sakata, K., Asai, S., Miyasaka, K., and Nakagawa, H. (1991). Dispersion of fillers and the electrical conductivity of polymer blends filled with carbon black. Polym. Bull. 25, 265-271. doi: 10.1007/BF00310802

Tambe, P. B., Bhattacharyya, A. R., and Kulkarni, A. R. (2013). The influence of melt-mixing process conditions on electrical conductivity of polypropylene/multiwall carbon nanotubes composites. J. Appl. Polym. Sci. 127, 1017-1026. doi: 10.1002/app.37889

Urquijo, J., Aranburu, N., Dagréou, S., Guerrica-Echevarria, G., and Eguiazábal, J. I. (2017). CNT-induced morphology and its effect on properties in PLA/PBAT-based nanocomposites. Eur. Polym. J. 93, 545-555. doi: 10.1016/j.eurpolymj.2017. 06.035

Xiong, Z. Y., Wang, L., Sun, Y., Guo, Z. X., and Yu, J. (2013). Migration of MWCNTs during melt preparation of $\mathrm{ABS} / \mathrm{PC} / \mathrm{MWCNT}$ conductive composites via PC/MWCNT master batch approach. Polymer 54, 447-455. doi: 10.1016/j.polymer.2012.11.044

Xu, P., Gui, H., Hu, Y., Bahader, A., and Ding, Y. (2014). Dielectric properties of polypropylene-based nanocomposites with ionic liquid-functionalized multiwalled carbon nanotubes. J. Electronic Mater. 43, 2754-2758. doi: 10.1007/s11664-014-3195-1

Zeimaran, E., Akbarivakilabadi, A., and Majumder, M. (2015). "Polystyrene Carbon nanotube composites," in Handbook of Polymer Nanocomposites. Processing, Performance and Application, Vol. 10, eds K. K. Kar, J. K. Pandey, and S. Rana (Berlin; Heidelberg: Springer-Verlag), 213. 
Zhang, C., Wang, P., Ma, C., Wu, G., and Sumita, M. (2006). Temperature and time dependence of conductive network formation: dynamic percolation and percolation time. Polymer 47, 466-473. doi: 10.1016/j.polymer.2005.11.053

Zhang, L., Wan, C., and Zhang, Y. (2009). Morphology and electrical properties of polyamide 6/polypropylene/multi-walled carbon nanotubes composites. Compos. Sci. Technol. 69, 2212-2217. doi: 10.1016/j.compscitech.2009. 06.005

Zhao, L., Li, Y., Cao, X., You, J., and Dong, W. (2012). Multifunctional role of an ionic liquid in melt-blended poly(methyl methacrylate)/multiwalled carbon nanotube nanocomposites. Nanotechnology 23:255702. doi: $10.1088 / 0957-4484 / 23 / 25 / 255702$
Conflict of Interest Statement: The authors declare that the research was conducted in the absence of any commercial or financial relationships that could be construed as a potential conflict of interest.

Copyright (c) 2019 Soares da Silva, Soares, Silva and Livi. This is an open-access article distributed under the terms of the Creative Commons Attribution License (CC $B Y)$. The use, distribution or reproduction in other forums is permitted, provided the original author(s) and the copyright owner(s) are credited and that the original publication in this journal is cited, in accordance with accepted academic practice. No use, distribution or reproduction is permitted which does not comply with these terms. 